Annales Geophysicae (2003) 21: 833-846 (C) European Geosciences Union 2003

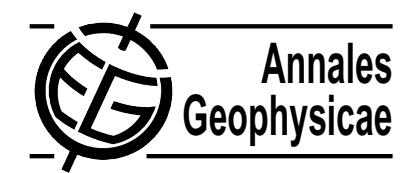

\title{
Sound speed in the Mediterranean Sea: an analysis from a climatological data set
}

\author{
S. Salon ${ }^{1}$, A. Crise ${ }^{1}$, P. Picco ${ }^{2}$, E. de Marinis ${ }^{3}$, and O. Gasparini ${ }^{3}$ \\ ${ }^{1}$ Istituto Nazionale di Oceanografia e di Geofisica Sperimentale-OGS, Borgo Grotta Gigante 42/C, I-34010 Sgonico-Trieste, \\ Italy \\ ${ }^{2}$ Centro Ricerche Ambiente Marino, CRAM-ENEA, S.Teresa, Località Pozzuolo di Lerici, I-19100, La Spezia, Italy \\ ${ }^{3}$ DUNE s.r.1., Via Tracia 4, I-00183 Roma, Italy
}

Received: 9 April 2002 - Revised: 26 August 2002 - Accepted: 18 September 2002

\begin{abstract}
This paper presents an analysis of sound speed distribution in the Mediterranean Sea based on climatological temperature and salinity data. In the upper layers, propagation is characterised by upward refraction in winter and an acoustic channel in summer. The seasonal cycle of the Mediterranean and the presence of gyres and fronts create a wide range of spatial and temporal variabilities, with relevant differences between the western and eastern basins. It is shown that the analysis of a climatological data set can help in defining regions suitable for successful monitoring by means of acoustic tomography. Empirical Orthogonal Functions (EOF) decomposition on the profiles, performed on the seasonal cycle for some selected areas, demonstrates that two modes account for more than $98 \%$ of the variability of the climatological distribution. Reduced order EOF analysis is able to correctly represent sound speed profiles within each zone, thus providing the a priori knowledge for Matched Field Tomography. It is also demonstrated that salinity can affect the tomographic inversion, creating a higher degree of complexity than in the open oceans.
\end{abstract}

Key words. Oceanography: general (marginal and semienclosed seas; ocean acoustics)

\section{Introduction}

Acoustic methods have been widely applied for underwater communication and for the remote observation of ocean interiors. The basin-scale ATOC project (Acoustic Thermometry of Ocean Climate; Munk, 1996; ATOC Consortium, 1998) has been one of the major applications of the acoustic tomographic approach for observing climate signal in the deep ocean. In the Western Mediterranean Sea, the ninemonths-long experiment THETIS-2 (Send et al., 1997) has estimated the seasonal heat budget, but this experience remains an unicum among tomographic Mediterranean basinscale studies. Convective events have been successfully ob-

Correspondence to: S. Salon (ssalon@ogs.trieste.it) served in the northwestern Mediterranean (Send et al., 1995) and in the Greenland Sea (Pawlowicz et al., 1995; Morawitz et al., 1996). Ocean acoustic tomography has also proved to be a methodology for the observation of currents and internal tides (Shang and Wang, 1994; Demoulin et al., 1997). These successful applications propose ocean tomography as a tool for large-scale monitoring of the oceans in the frame of the development of Global Oceans Observing Systems (GOOS).

In spite of this growing interest in acoustic inversion, an analysis of the sound speed field in the Mediterranean Sea is still lacking. The aim of this paper is to provide a description of sound speed characteristics (and a first guess on the sound speed structure) in the Mediterranean Sea, its seasonal variability and spatial distribution, starting from a climatological data set of temperature and salinity. Furthermore, the analysis of the climatological data set will lead to the consideration of the following three issues:

1. The climatological sound speed profiles (SSPs) represent a good quality reference to be used as an initial condition for the environmental parameters in propagation models and for the solution of inverse problems.

2. The SSP analysis can help in designing tomographic experiments, while EOF analysis, which estimates the number of significant modes to be taken into consideration for each area, provides a base for Matched Field Tomography (Munk et al., 1995).

3. The knowledge of the dependence of sound speed on both salinity and temperature climatological profiles allows a more precise inversion than the temperaturebased one alone.

\section{Methodology}

\subsection{Mediterranean Oceanic data base - MED6 data set}

The analysis performed in this work is based on MED6 (Brankart and Pinardi, 2001), a gridded analysis of monthly 
Table 1. Numerical coefficients of the MacKenzie sound speed formula (1981)

\begin{tabular}{ll}
\hline $\mathrm{A}$ & $1448.96 \mathrm{~m} \mathrm{~s}^{-1}$ \\
$\mathrm{~B}$ & $4.591 \mathrm{~m} \mathrm{~s}^{-1 \circ} \mathrm{C}^{-1}$ \\
$\mathrm{C}$ & $-5.304 \cdot 10^{-2} \mathrm{~m} \mathrm{~s}^{-1}{ }^{\circ} \mathrm{C}^{-2}$ \\
$\mathrm{D}$ & $2.374 \cdot 10^{-4} \mathrm{~m} \mathrm{~s}^{-1}{ }^{\circ} \mathrm{C}^{-3}$ \\
$\mathrm{E}$ & $1.340 \mathrm{~m} \mathrm{~s}^{-1}$ \\
$\mathrm{~F}$ & $1.630 \cdot 10^{-2} \mathrm{~s}^{-1}$ \\
$\mathrm{G}$ & $1.675 \cdot 10^{-7} \mathrm{~m}^{-1} \mathrm{~s}^{-1}$ \\
$\mathrm{H}$ & $-1.025 \cdot 10^{-2} \mathrm{~m} \mathrm{~s}^{-1 \circ} \mathrm{C}^{-1}$ \\
$\mathrm{~J}$ & $-7.139 \cdot 10^{-13} \mathrm{~m}^{-2} \mathrm{~s}^{-1 \circ} \mathrm{C}^{-1}$ \\
\hline
\end{tabular}

estimates of the climatological cycle of in situ temperature and salinity for the whole Mediterranean and the near North Atlantic area at $\frac{1}{4}{ }^{\circ}$ resolution. MED6 is based on the MEDATLAS historical database (MEDATLAS Group, 1994). The data set is obtained using the statistical analysis scheme developed for the Mediterranean Oceanic Data Base (MODB; Brasseur et al., 1996), where a Gaussian time correlation function has been introduced to enhance the time coherence of the solution. The main additional information contained in the MEDATLAS data set comes from the inclusion of about 80000 XBTs, bringing the total number of temperature profiles from 120000 to about 200000 . We have applied some small adjustments to the data set: in particular, some temperature values in the Adriatic appeared to be too high and an additional check in the gridded data set for that region was done. Comparing the mean summer temperature at $200 \mathrm{~m}$ with a recent climatological study of the Adriatic Sea (Giorgetti, 1999), it was decided to eliminate from the original gridded data set all the grid boxes in this area with temperature values higher than $14.3^{\circ} \mathrm{C}$.

\subsection{Sound speed computation}

Several formulas have been proposed to compute sound speed (also referred as SS) from temperature, salinity, and pressure or depth in the sea water (Del Grosso, 1974; Clay and Medwin, 1977; MacKenzie, 1981; Chen and Millero, 1977). In the range of interest for the Mediterranean Sea, differences among formulas higher than $1.2 \mathrm{~m} / \mathrm{s}$ are found at great depths, while in the surface layers the discrepancy never exceeds $0.2 \mathrm{~m} / \mathrm{s}$. For this work the one from MacKenzie (1981) was chosen: it is computationally efficient and has an accuracy of about $0.1 \mathrm{~m} / \mathrm{s}$ (Dushaw et al., 1993). It is more accurate than that from Clay and Medwin (1977), proposed as a standard for tomographic applications by Jensen et al. (1994), and in the meantime it is suitable for analytical inversion:

$$
\begin{gathered}
c(T, S, z)=A+B T+C T^{2}+D T^{3}+E(S-35) \\
+F z+G z^{2}+H T(S-35)+J T z^{3},
\end{gathered}
$$

where $c$ is sound speed $(\mathrm{m} / \mathrm{s}), T$ is temperature $\left({ }^{\circ} \mathrm{C}\right), S$ is salinity and $z$ is depth $(\mathrm{m})$. The coefficients are reported in
Table 1. Sound speed has been computed for each grid point and for each month of the MED6 data set, and from this field the annual average was also obtained.

\subsubsection{Error analysis}

The error on sound speed computation associated with the uncertainty on temperature, salinity and depth, can be estimated by the error propagation formula:

$$
\begin{aligned}
\Delta c & =\frac{\partial c}{\partial T} \Delta T+\frac{\partial c}{\partial S} \Delta S+\frac{\partial c}{\partial z} \Delta z \\
& =\left(B+2 C T+3 D T^{2}+H(S-35)+J z^{3}\right) \Delta T+ \\
& =(E+H T) \Delta S+\left(F+2 G z+3 J T z^{2}\right) \Delta z
\end{aligned}
$$

The contribution of depth uncertainty can be safely neglected, and we consider $\Delta T$ and $\Delta S$ to be approximately one order of magnitude larger than the modern CTD standard $\left(\Delta T=0.05^{\circ} \mathrm{C}\right.$ and $\left.\Delta S=0.05\right)$, to include the intrinsic errors of some historical measurements. In the wide ranges of 5-30 ${ }^{\circ} \mathrm{C}$ and $34-39$, the maximum error is slightly more than $0.26 \mathrm{~m} / \mathrm{s}$.

Since the MacKenzie formula is nonlinear, the operations of the averaging process and SS computation do not commute strictu sensu. The computations carried out in this work were instead obtained by first interpolating $T$ and $S$ on the regular grid and then deriving SS. This can be justified because in this way the information contained in the measurements can be better exploited also when only temperature or salinity is available. At the same time, this work can take full advantage of the data quality control and analysis carried out on the $T$ and $S$ fields. Last, but not least, the commutation error can be neglected, as is demonstrated hereafter.

Assuming that the depth measures are error-free, we identify the $\mathrm{T}$ and $\mathrm{S}$ fields of the gridded data set with an overbar, since the gridding adopted is a weighted linear average. In the following we consider that the weights are equal, as the spatial distribution of the samples is assumed to be homogeneous. This assumption is corroborated by the vast amount of data available. Using Eq. (1) the average SS based on the gridded data set $\left(c_{G}\right)$ is, therefore

$$
\begin{aligned}
& \overline{c_{G}(T, S, z)}=A+B \bar{T}+C \bar{T}^{2}+D \bar{T}^{3}+E(\bar{S}-35) \\
& \quad+F z+G z^{2}+H \bar{T}(\bar{S}-35)+J \bar{T} z^{3} .
\end{aligned}
$$

In the case of the SS calculation from the original measurements, the averaged sound speed $\left(c_{M}\right)$ reads:

$$
\begin{aligned}
& \overline{c_{M}(T, S, z)}=\overline{A+B T+C T^{2}+D T^{3}+E(S-35)} \\
& \quad \overline{+F z+G z^{2}+H T(S-35)+J T z^{3}} \\
& \quad=A+B \bar{T}+C \overline{T^{2}}+D \overline{T^{3}}+E(\bar{S}-35) \\
& \left.\quad+F z+G z^{2}+H \overline{T(S}-35\right)+J \bar{T} z^{3} .
\end{aligned}
$$

The error introduced is the absolute difference between the average calculated on the measures (4) and that one estimated directly on the gridded data set (3), and depends only on the nonlinear terms:

$\left|\overline{c_{M}}-\overline{c_{G}}\right|=\left|C\left(\overline{T^{2}}-\bar{T}^{2}\right)+D\left(\overline{T^{3}}-\bar{T}^{3}\right)+H(\overline{T S}-\overline{T S})\right|(5)$ 
The first term on the right-hand side is simply the variance of the temperature $\left(\sigma_{T}^{2}\right)$. The second term can be developed further assuming that $T=\bar{T}+T^{\prime}$, where $T^{\prime}$ represents the fluctuation associated with the measure (assumed zero-mean normally distributed stochastic process), we have:

$$
\begin{gathered}
\overline{T^{3}}-\bar{T}^{3}=\overline{\left(\bar{T}+T^{\prime}\right)^{3}}-\bar{T}^{3}=\overline{\bar{T}^{3}+T^{\prime 3}+3 \bar{T}^{2} T^{\prime}} \\
\overline{+3 \bar{T} T^{\prime 2}}-\bar{T}^{3}= \\
\overline{T^{\prime 3}}+3 \bar{T}^{2} \overline{T^{\prime}}+3 \bar{T} \overline{T^{\prime 2}}=3 \bar{T} \sigma_{T}^{2} .
\end{gathered}
$$

The first term in Eq. (6) is the skewness that is zero for a normal distribution; the second is also zero because the fluctuation is supposed to be zero-mean; the third is proportional to the variance of temperature. The mixed term of temperature and salinity is treated in a similar way, assuming that $S=\bar{S}+S^{\prime}$ (with the same statistical properties of $T^{\prime}$ ):

$$
\begin{aligned}
\overline{T S}-\overline{T S}=\overline{\left(\bar{T}+T^{\prime}\right)\left(\bar{S}+S^{\prime}\right)}-\overline{T S}= \\
\overline{\left(\overline{T S}+T^{\prime} \bar{S}+\bar{T} S^{\prime}+T^{\prime} S^{\prime}\right)}-\overline{T S}=\overline{T^{\prime} S^{\prime}},
\end{aligned}
$$

which could be neglected assuming incorrelated fields of temperature and salinity anomalies. The expression (5) thus reduces to:

$$
\left|\overline{c_{M}}-\overline{c_{G}}\right|=\left|C \sigma_{T}^{2}+3 D \bar{T} \sigma_{T}^{2}\right|=\sigma_{T}^{2}|C+3 D \bar{T}| .
$$

Assuming, for example, a temperature value of $20^{\circ} \mathrm{C}$ and taking its variance equal to $1^{\circ} \mathrm{C}^{2}$, in order to take into account the approximations adopted (this value is twice that of the one found in Brankart and Pinardi, 2001, for the same data set), we obtain an error of $0.05 \mathrm{~m} / \mathrm{s}$, which is one order of magnitude lower than the uncertainty associated with the formula. As a summary, the total error associated with the computation of the SS field is obtained by:

$\sqrt{A^{2}+\Delta c^{2}+\left|\overline{c_{M}}-\overline{c_{G}}\right|^{2}} \approx 0.28 \mathrm{~m} / \mathrm{s}$,

where $A$ is the accuracy of $0.1 \mathrm{~m} / \mathrm{s}$, and the second and third terms come from Eqs. (2) and (8).

\subsubsection{Salinity uncertainty}

An estimate of the importance of salinity uncertainty in the tomographic inversion process can be appraised using the SS sensitivity expressed in Eq. (2). A development of the value of SS in terms of the salinity anomaly in a Taylor series can be truncated at the first order, since Eq. (1) is linear in $S$. The SS anomaly with respect to salinity, $\left|c(S(\boldsymbol{x}, t))-c\left(S_{0}\right)\right|$, where $(\boldsymbol{x}, t)$ represents the data location and time and $S_{0}$ is the mean value below defined, is then linearly dependent on the salinity anomaly weighted by the SS derivative with respect to $S$ and is equal to $\left|(E+H T(\boldsymbol{x}, t))\left(S(\boldsymbol{x}, t)-S_{0}\right)\right|$.

To estimate the SS anomaly for the upper layer of the Mediterranean, we have calculated from the MED6 data set the absolute values of the deviation of salinity with its vertical average. For the sake of simplicity, we use the continuous formulation:

$\Delta S(\boldsymbol{x}, t)=\left|S(\boldsymbol{x}, t)-S_{0}\right|$ with $S_{0}=\frac{1}{B} \int_{-B}^{0} S(\boldsymbol{x}, t) d z$,
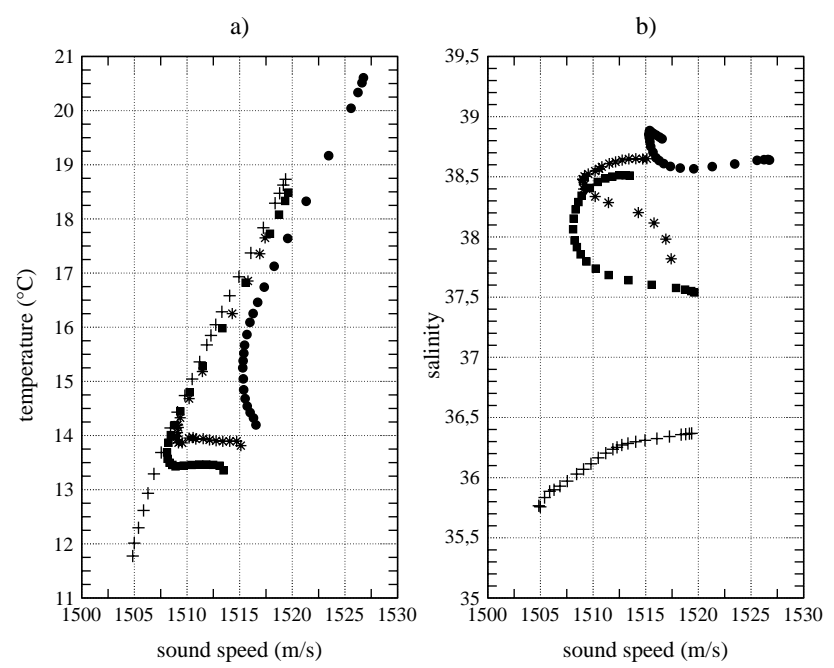

Fig. 1. Scatter plot of areal annual means in the North Atlantic (+), West Mediterranean (ם), East Mediterranean (•) and Adriatic Sea $(*)$, between 5 and $500 \mathrm{~m}$ of (a) temperature $\left({ }^{\circ} \mathrm{C}\right)$ and sound speed $(\mathrm{m} / \mathrm{s})$ and (b) salinity and sound speed $(\mathrm{m} / \mathrm{s})$

where the integral was taken over the entire water column (between bottom, "-B", and surface). Then spatial and temporal averages of the salinity anomaly are computed for the upper $700 \mathrm{~m}$, where the variability is larger, and where the acoustic methods can be applied to resolve the seasonal cycle, obtaining a value of $\overline{\Delta S}=0.177$. With the salinity deviation estimate given by Eq. (10), the following basin-wide climatological anomaly is obtained:

$\left|c(S(\boldsymbol{x}, t))-c\left(S_{0}\right)\right|=|(E+H \bar{T}) \overline{\Delta S}|=0.21 \mathrm{~m} / \mathrm{s}$,

where $\bar{T}=14.7^{\circ} \mathrm{C}$ is the spatial average of the climatological temperature in the upper $700 \mathrm{~m}$. It is worth noting that the average salinity deviation $\overline{\Delta S}$ introduces an error in the SS calculation of the same order as that one obtained just by substituting each salinity profile with its (spatial- and temporaldependent) mean,as estimated in Eq. (9). A better resolution is needed to distinguish between different water masses in deeper layers, where the typical variability of temperature and salinity affects the sound speed by less than $0.5 \mathrm{~m} / \mathrm{s}$.

To characterise the relation of sound speed with temperature and salinity, plots of sound speed versus temperature (Fig. 1a) and versus salinity (Fig. 1b) for different areas, have been analysed. Four subsets of the data set, corresponding to the two main sub-basins, namely the Western Mediterranean $\left(5.5^{\circ} \mathrm{W}-12^{\circ} \mathrm{E}\right.$ and $\left.32^{\circ} \mathrm{N}-44.5^{\circ} \mathrm{N}\right)$, the Eastern Mediterranean $\left(12^{\circ} \mathrm{E}-36^{\circ} \mathrm{E}\right.$ and $\left.30.5^{\circ} \mathrm{N}-38^{\circ} \mathrm{N}\right)$, a regional sea, the Adriatic Sea $\left(12^{\circ} \mathrm{E}-19.5^{\circ} \mathrm{E}\right.$ and $40.5^{\circ} \mathrm{N}-$ $45.5^{\circ} \mathrm{N}$ ) and, as a comparison, the area of the North Atlantic, west of Gibraltar Strait $\left(9.375^{\circ} \mathrm{W}-5.5^{\circ} \mathrm{W}\right.$ and $\left.34^{\circ} \mathrm{N}-38^{\circ} \mathrm{N}\right)$ were considered. To highlight the differences, the spatial averaged annual mean SS profiles and the corresponding value of temperature and salinity were obtained for each level from a 5 to $500 \mathrm{~m}$ depth and reported as $T / \mathrm{SS}$ and $S / \mathrm{SS}$ diagrams. The scatter plots, in Fig. 1, evidence significant dif- 
ferences between the North Atlantic region and the Mediterranean. In the North Atlantic, apart from the near-surface layer, the curve is monotonic, with a quite linear dependence for both temperature and salinity, and the range of variability of sound speed is limited between 1505 and $1520 \mathrm{~m} / \mathrm{s}$. In the Mediterranean Sea, the dependence of sound speed on temperature and salinity in the thermocline region is more complicated, with a peculiar behaviour for each selected basin, thus making it complex to estimate the temperature from the sound speed without a good TS statistic of the interested area. In both the western and eastern basins no relation of sound speed with temperature can be found in the upper layer, as a negligible variation of sound speed corresponds to a wide temperature interval (up to $1.5^{\circ} \mathrm{C}$ close to $1515 \mathrm{~m} / \mathrm{s}$ in the eastern basin); the same occurs for salinity in the western part, up to 0.5 around $1508 \mathrm{~m} / \mathrm{s}$. In the eastern basin, the presence of the LIW can be evidenced by a minimum sound speed $(1515 \mathrm{~m} / \mathrm{s})$ corresponding to temperature and salinity values higher than those relative to the minimum of sound speed in the western basin (between 1507 and $1508 \mathrm{~m} / \mathrm{s}$ ), where the minimum corresponds to the thermocline. Below the thermocline, where temperature and salinity are almost constant with depth, the wide variability of sound speed is mainly due to pressure effects.

\subsection{EOF decomposition}

Empirical Orthogonal Function (EOF) decomposition represents an efficient approach to SSP parameterisation and is widely used in many Ocean Acoustic Tomography (OAT) or Matched Field applications (Shang and Wang, 1994), since it permits the description of a complex variable field as a linear combination of a few eigenfunctions, a crucial issue when a reduced parameter space is needed to solve the inverse problem. The structure of the SSP is statistically explained by a few orthogonal functions (vertical eigenfunctions) which cannot always be easily interpreted as the contribution of distinct dynamical mechanisms acting on the water column structure. EOF analysis decouples the spatial component from the temporal one, thus enabling an immediate interpretation of the SSP seasonal evolution. The analysis of the eigenvalues' distribution allowed us to select the relative weight of the dominating EOFs, as the smaller eigenvalues are generally associated with noise and sampling errors. EOF analysis not only speeds up tomographic inversion, but also avoids the introduction of unwanted components in the inversion. In this work, EOF analysis has been applied to spatially averaged vertical profiles $c(z)$ of sound speed in 14 different regions described in Sect. 3.2. The vertical EOFs were computed by using the traditional methodology proposed, among others, by Davis (1976) and Weare et al. (1976), and here summarized:

$c(z)=c_{0}(z)+\Delta c(z)$

where the monthly mean sound speed profile $c(z)$ has been decomposed in an annual mean value $c_{0}(z)$ plus a perturba- tion term $\Delta c(z)$, expressed as:

$\Delta c(z)=\sum_{i=1}^{N} \alpha_{i}(t) F_{i}(z)$.

In Eq. (13), $\alpha_{i}(t)$ are the time coefficients, $F_{i}(z)$ represent the vertical eigenfunctions and $N$ is the number of possible modes, which in our case coincides with the number of levels relative to each area (maximum is $N=34$ ).

In the case of a gridded data set, obtained from an objective analysis based on the Gauss-Markov estimation (as for MODB-MED6), the expected value of the deviation $\Delta c(z)$ calculated from the data set itself can be better than those obtained using only measurements. In other words, we can apply the EOF analysis on the gridded data instead of on the measured set without incurring, on average, additional errors. Proof for a generic vertical profile, of scalar quantity in the case of a gridded data set, is given in Appendix A. This proof constitutes a validation of our approach and guarantees the reliability of the EOF computation.

\section{Results}

3.1 Sound speed distribution: annual mean and seasonal variability

This analysis focuses on the layer between 50 and $400 \mathrm{~m}$, since - in terms of acoustic propagation - in the upper mixed layer the acoustic wave undergoes a near-surface upward refraction; therefore and it is not exploitable for tomographic applications, while in the deeper layers sound speed differences are not strong enough to be resolved by this methodology.

Horizontal spatial distribution of annual mean sound speed at a $50 \mathrm{~m}$ depth (Fig. 2) clearly displays a northwest to southeast gradient, with values between 1506 and $1508 \mathrm{~m} / \mathrm{s}$ located in the Gulf of Lions, a minimum of $1505 \mathrm{~m} / \mathrm{s}$ in the northern Adriatic Sea, and a maximum of up to $1527 \mathrm{~m} / \mathrm{s}$ on the easternmost Mediterranean coast. Persistent features such as fronts and gyres perturb the climatological SS mean field (Liguro-Provençal Basin, Balearic Front, Cretan and Rhodes Gyres separated by the maximum relative to the Ierapetra Gyre).

Zonal and meridional SS annual averages between 5 and $160 \mathrm{~m}$ are shown in Fig. 3, where an SS increment southward (Fig. 3a) and eastward (Fig. 3b) clearly appears. In general the two basins have rather homogeneous gradients, even if the absolute values are quite different. In Fig. 3b, three areas can be clearly identified, starting from the western side of the plot: the North Atlantic one, up to $5.5^{\circ} \mathrm{W}$, divided by the Mediterranean by a sharp discontinuity, the western basin with a relatively constant SS up to $13^{\circ} \mathrm{E}$, and the eastern basin characterized by a negative gradient.

In Fig. 4 we show the entire annual SS mean profiles up to $2350 \mathrm{~m}$ with the aim of discussing differences in the deeper layers. The profiles are averaged on the three Mediterranean sub-basins, previously defined, the whole Mediter- 


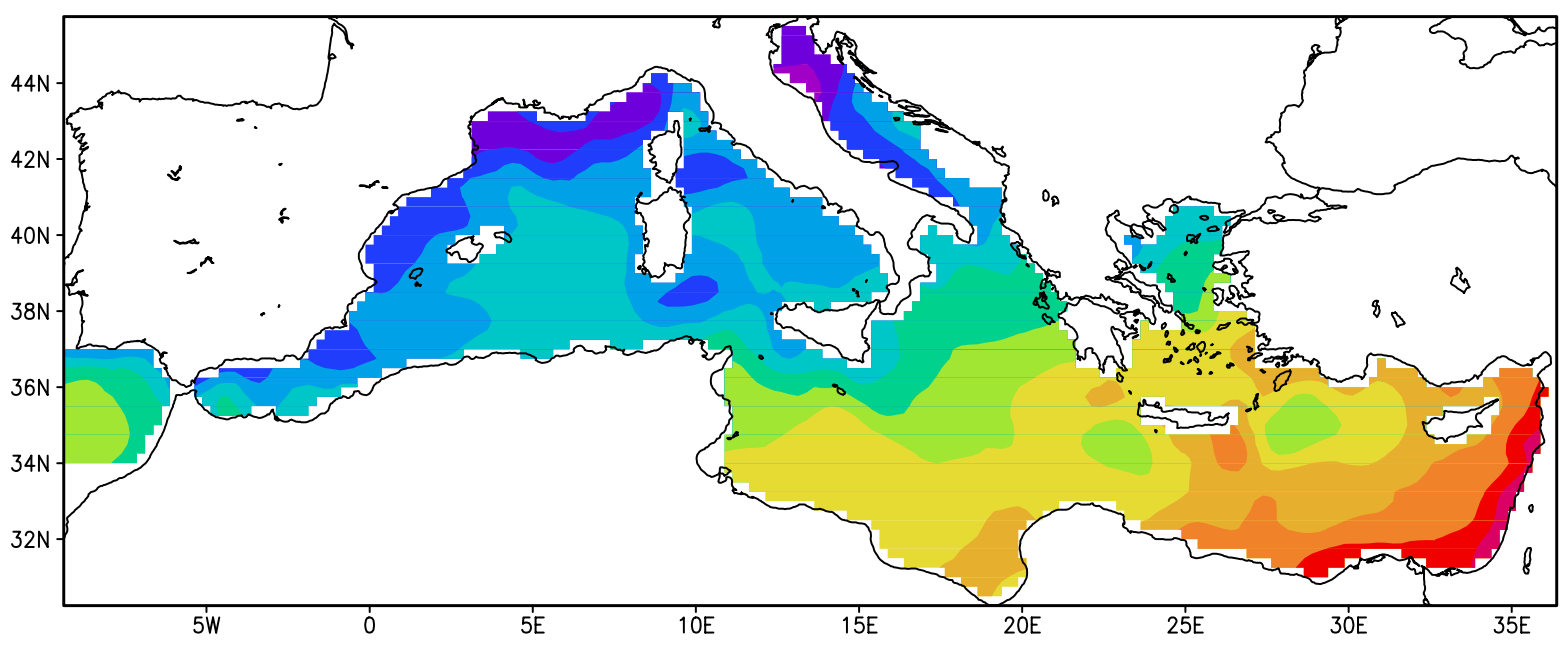

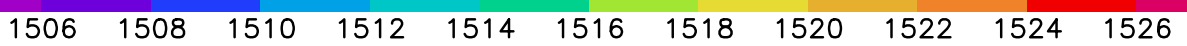

Fig. 2. Sound speed annual mean at $50 \mathrm{~m}$.
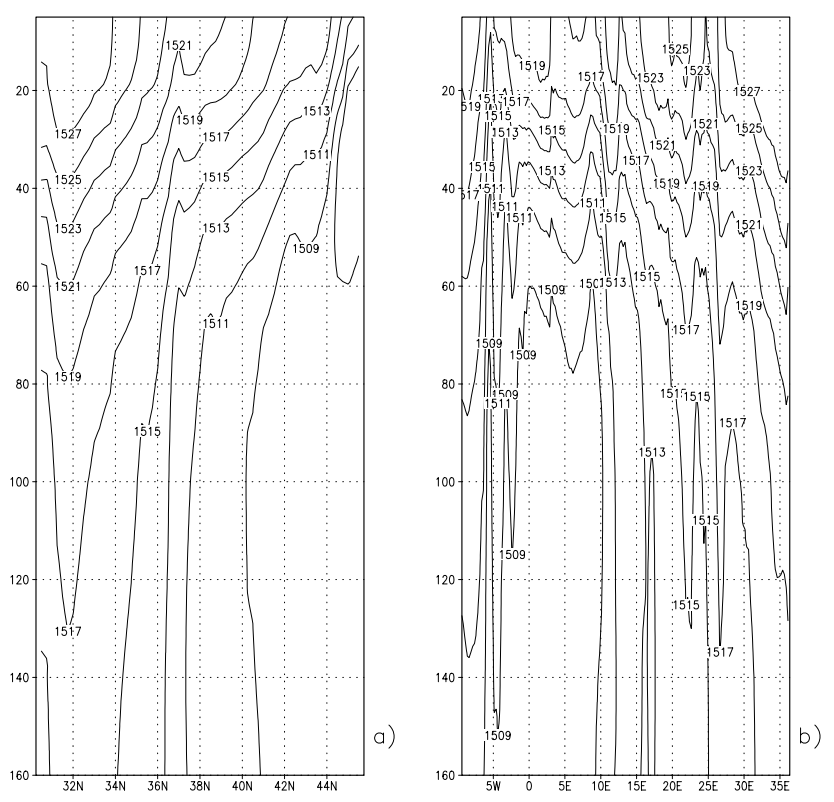

Fig. 3. Annual sound speed (m/s) between 5 and $160 \mathrm{~m}$ : (a) zonal mean between 30.25 and $45.75^{\circ} \mathrm{N}$; (b) meridional mean between $9.375^{\circ} \mathrm{W}$ and $36.375^{\circ} \mathrm{E}$.

ranean profile, and, for comparison, the North Atlantic area, west of Gibraltar. The Mediterranean basins' profiles are characterized by a surface layer with strong decreasing values, a minimum located at the base of the seasonal thermocline and a slow but constant increase due to the effect of pressure. In terms of sound propagation, this means a channelled propagation below thermocline. Decreasing down below $600 \mathrm{~m}$ the vertical gradient is practically constant (about $1 \mathrm{~m} / \mathrm{s}$ every 60 metres of depth, in very good agreemeent with

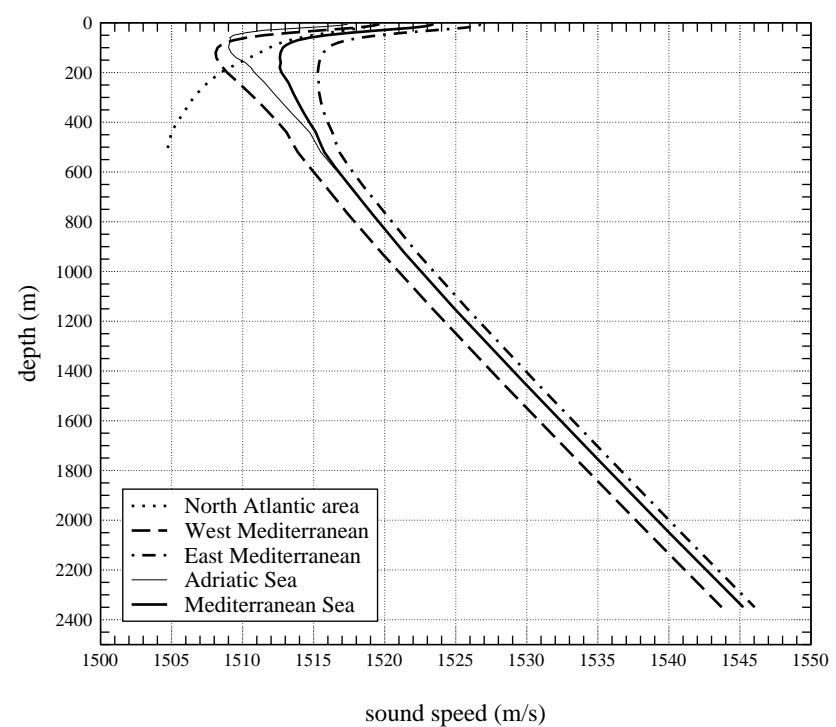

Fig. 4. Sound speed annual mean profiles $(\mathrm{m} / \mathrm{s})$ between 5 and $2350 \mathrm{~m}$, spatially averaged on the West Mediterranean, the East Mediterranean, the Adriatic Sea, the whole Mediterranean Sea, and the North Atlantic area west of Gibraltar.

the value of $0.0167 \mathrm{~s}^{-1}$ calculated by Jensen et al. (1994) for a mean Mediterranean profile) due to the dominant role of pressure dependency. The minimum values are found at the base of the thermocline at about $120 \mathrm{~m}$ depth in the western basin $(1508.1 \mathrm{~m} / \mathrm{s})$ and around $100 \mathrm{~m}$ in the Adriatic Sea $(1509 \mathrm{~m} / \mathrm{s})$, while the profile from the eastern basin shows an almost uniform layer from $150 \mathrm{~m}$ to $280 \mathrm{~m}$ in correspondence to the minimum $(1515.3 \mathrm{~m} / \mathrm{s})$. At a $200 \mathrm{~m}$ depth in the Adriatic Sea, SS is modified by the presence of the signature of Levantine Intermediate Water, found in all profiles around 

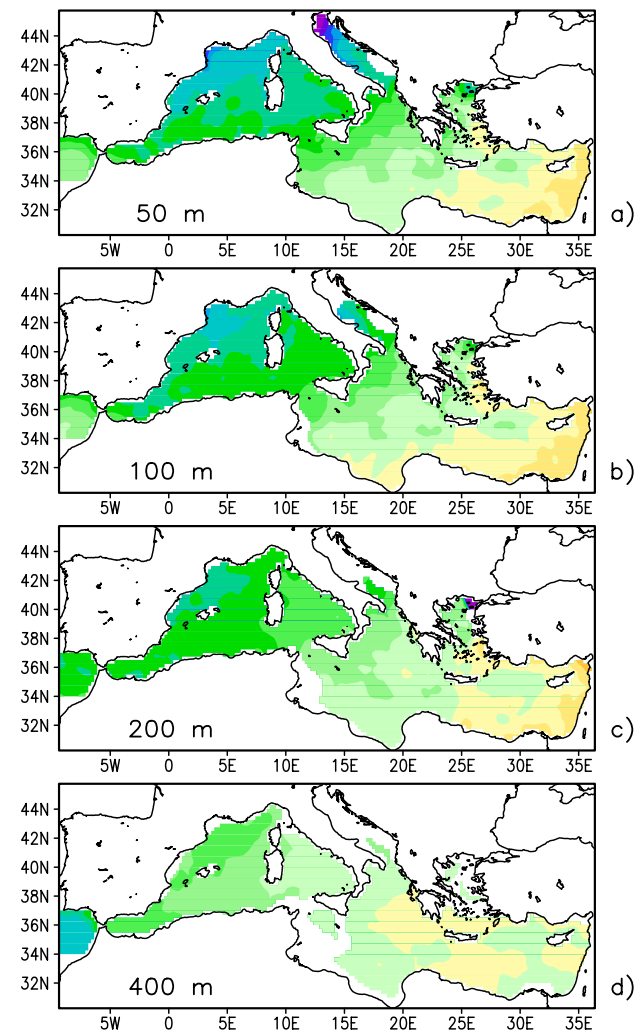

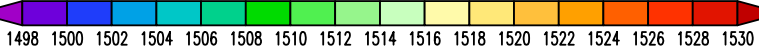

Fig. 5. Sound speed monthly mean $(\mathrm{m} / \mathrm{s})$ in February at $50 \mathrm{~m}$ (a), $100 \mathrm{~m} \mathrm{(b),} 200 \mathrm{~m} \mathrm{(c)} \mathrm{and} 400 \mathrm{~m}(\mathbf{d})$.

$500 \mathrm{~m}$ : the presence of this warmer and saltier water only determines a small variation in the derivative of the sound speed profile.

The SS seasonal variability can be represented by the two extreme situations found in February (Fig. 5) and August (Fig. 6), respectively, at $50 \mathrm{~m}$ (a), $100 \mathrm{~m} \mathrm{(b),} 200 \mathrm{~m}$ (c) and $400 \mathrm{~m}$ (d). In February, at $50 \mathrm{~m}$, SS ranges from values lower than $1498 \mathrm{~m} / \mathrm{s}$, up to $1520 \mathrm{~m} / \mathrm{s}$, with the lower limit strongly localised in the northern Adriatic in correspondence with the Po River outflow, and the higher one being located in the eastern Levantine basin. Winter SS distribution in the northwestern Mediterranean has the same patterns at all the depths, due to the vertically homogeneous distribution of water masses, with some increasing for the effect of pressure.

In August, at $50 \mathrm{~m}$, SS generally increases all over the basin, ranging from $1506 \mathrm{~m} / \mathrm{s}$ up to the maximum climatological velocity of $1530 \mathrm{~m} / \mathrm{s}$ located offshore of the Israeli coast. No important differences between winter and summer situations can be observed at $400 \mathrm{~m}$, as the effects of the seasonal cycle do not reach these depths; some variability is linked to the presence of LIW, values as high as those of the eastern basin are also found in the Tyrrhenian Sea and even offshore of the western coast of Sardinia. The difference between the North Atlantic sector and Gibraltar becomes important in the deeper layers, due to the contrast between the Atlantic waters
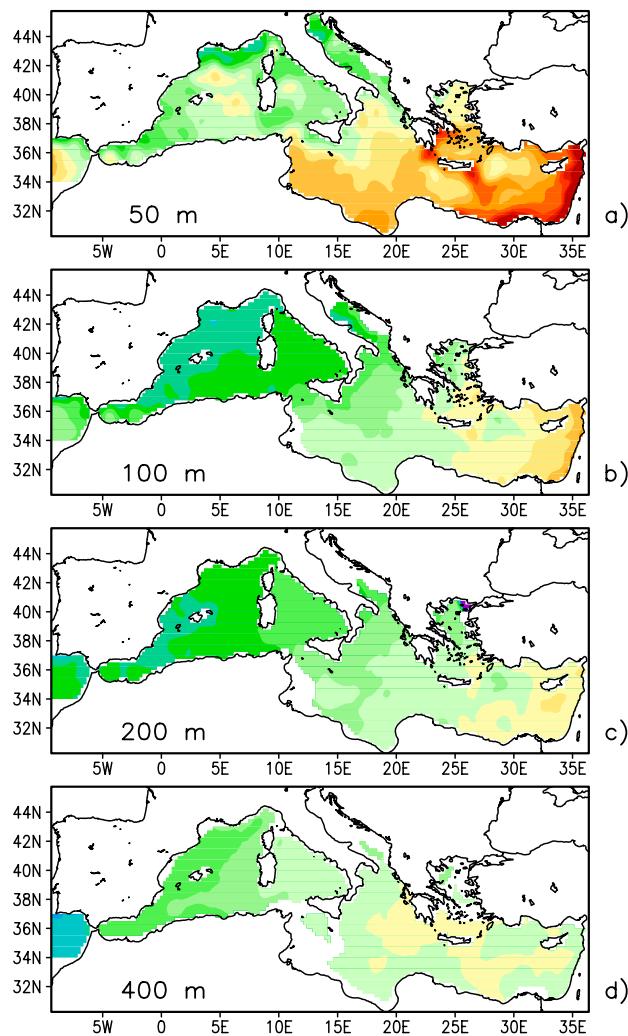

$149815001502150415061508151015121514 \quad 1516 \quad 151815201522 \quad 1524 \quad 152615281530$

Fig. 6. Sound speed monthly mean $(\mathrm{m} / \mathrm{s})$ in August at $50 \mathrm{~m}(\mathbf{a})$, $100 \mathrm{~m}$ (b), $200 \mathrm{~m}$ (c) and $400 \mathrm{~m}$ (d).

and the warmer and saltier Mediterranean outflow.

The SS standard deviation relative to the 50, 100, 200 and $400 \mathrm{~m}$ depths (Figs. 7a-d) allows us to identify areas where the seasonal signal is strong enough to be detected by acoustic tomography. It is significant at $50 \mathrm{~m}$ for the whole basin, with deviations between 1.5 and $7 \mathrm{~m} / \mathrm{s}$, while in the deeper layers it is relevant only for the southern Portuguese coast in the North Atlantic (values up to $1.6 \mathrm{~m} / \mathrm{s}$ even at $400 \mathrm{~m}$ depth) and, to a lower extent, for the Ierapetra Gyre $(0.8 \mathrm{~m} / \mathrm{s})$, and the southeastern coast $(1 \mathrm{~m} / \mathrm{s})$ of the Levantine basin. At $50 \mathrm{~m}$ the mean SS anomaly in the Mediterranean Sea is $3.7 \mathrm{~m} / \mathrm{s}$, but there are regions with deviations higher than $6 \mathrm{~m} / \mathrm{s}$ (the Balearic basin, the African Shelf in the Strait of Sicily, the southwestern Aegean Sea, the Ierapetra gyre, the easternmost Mediterranean coasts). At $100 \mathrm{~m}$ the absolute maximum of the anomaly (higher than $6 \mathrm{~m} / \mathrm{s}$ ) is located in proximity of the Ierapetra gyre, while the central Adriatic Sea reaches values up to $2.5 \mathrm{~m} / \mathrm{s}$. The rest of the Mediterranean basin shows values lower than $2 \mathrm{~m} / \mathrm{s}$ in the western part, and between 0.5 and $2 \mathrm{~m} / \mathrm{s}$ in the eastern one (the mean value in the whole Mediterranean at this depth is of the order of $0.9 \mathrm{~m} / \mathrm{s}$ ). The seasonal variability, however, appears stronger in the Eastern Mediterranean.

At $200 \mathrm{~m}$ the field appears uniform, presenting a mean value of the anomaly around $0.45 \mathrm{~m} / \mathrm{s}$, with some isolated 

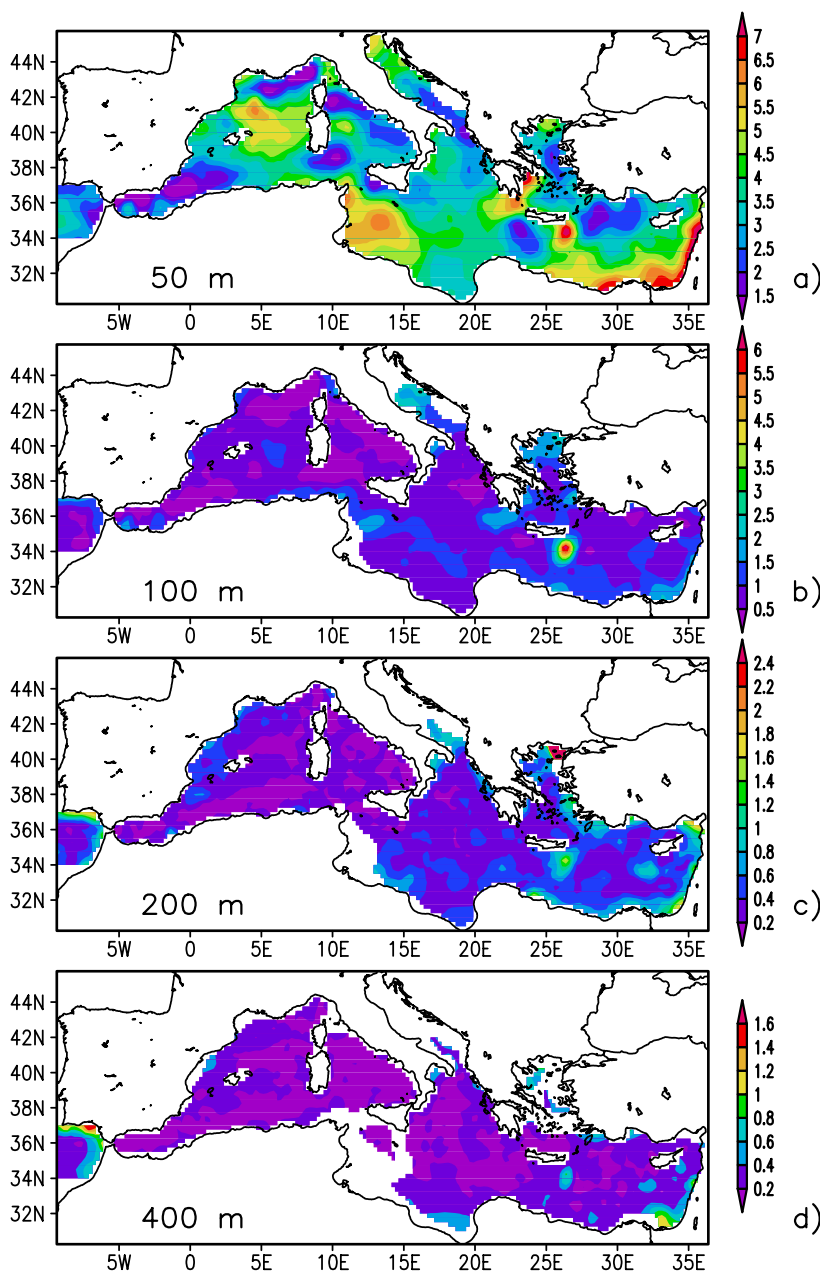

Fig. 7. Spatial distribution of sound speed standard deviation $(\mathrm{m} / \mathrm{s})$ at $50 \mathrm{~m} \mathrm{(a),} 100 \mathrm{~m} \mathrm{(b),} 200 \mathrm{~m} \mathrm{(c)} \mathrm{and} 400 \mathrm{~m}$ (d).

maxima south of Portugal $(2 \mathrm{~m} / \mathrm{s})$ and in the Eastern Mediterranean, in correspondence to the Ierapetra gyre $(1.6 \mathrm{~m} / \mathrm{s})$ and the Israeli and southeastern Turkish coasts $(2 \mathrm{~m} / \mathrm{s})$. The Dardanelles Strait presents extremely high values compared to the rest of the Mediterranean (of the order of $30 \mathrm{~m} / \mathrm{s}$, due to the freshwater outflow of the Black Sea), but it is not represented on the maps, in order to have a good resolution for the rest of the basin. At $400 \mathrm{~m}$ the whole Mediterranean basin presents a standard deviation of around $0.25 \mathrm{~m} / \mathrm{s}$, with a few exceptions (the Spanish Atlantic coast, up to $1.6 \mathrm{~m} / \mathrm{s}$, the eastern Egyptian and northern Israeli coasts, up to $1.2 \mathrm{~m} / \mathrm{s}$ ). The signal of the Ierapetra gyre is still recognizable, with relative values lower than $0.8 \mathrm{~m} / \mathrm{s}$.

\subsection{Zonation}

The zonation of the Mediterranean Sea (Fig. 8) was chosen according to the guidelines proposed by Le Vourch et al. (1992) for the identification of the front in the thermal satellite images. The choice of upper layer thermal structure as a discriminant for the zonation is supported by the analysis
Table 2. Standard deviations from the annual mean higher than $1.5 \mathrm{~m} / \mathrm{s}$ at depths of $50,100,200$ and $400 \mathrm{~m}$, for each region

\begin{tabular}{ccccc}
\hline & $50 \mathrm{~m}$ & $100 \mathrm{~m}$ & $200 \mathrm{~m}$ & $400 \mathrm{~m}$ \\
\hline NA & $\bullet$ & $\bullet$ & $\bullet$ & $\bullet$ \\
ALB & $\bullet$ & $\bullet$ & & \\
ALG & $\bullet$ & & & \\
BAL & $\bullet$ & & & \\
LIO & $\bullet$ & $\bullet$ & & \\
NTH & $\bullet$ & $\bullet$ & & \\
STH & $\bullet$ & & & \\
SIC & $\bullet$ & $\bullet$ & & \\
TUN & $\bullet$ & $\bullet$ & & \\
NAD & $\bullet$ & $\bullet$ & & \\
SAD & $\bullet$ & $\bullet$ & & \\
ION & $\bullet$ & $\bullet$ & & \\
AEG & $\bullet$ & $\bullet$ & & \\
SEM & $\bullet$ & $\bullet$ & $\bullet$ & \\
\hline
\end{tabular}

of annual mean SSPs and their seasonal variability described above, since the variability is essentially associated with the upper layer. In addition, the bottom topography, the general knowledge of water masses' distribution and the climatological dynamic conditions helped us in defining the areas.

The spatially averaged SS values and standard deviation of the 14 areas have been computed at each level and for each month, in order to obtain the SSP seasonal cycle for each area. The vertical distribution of the spatial standard deviation $\sigma_{x}$ for the annual mean (not shown) is used to express the goodness of the zonation, thus constituting a validation of the choice in defining the areas. The obtained values are of the order of $1-2 \mathrm{~m} / \mathrm{s}$ in the upper levels, up to $20 \mathrm{~m}$, increasing to $1.5-2.5 \mathrm{~m} / \mathrm{s}$ between 20 and $60 \mathrm{~m}$, reaching the maximum between 30 and $40 \mathrm{~m}$ (except at the Alboran Sea at $15 \mathrm{~m}$, North and South Adriatic Sea at $20 \mathrm{~m}$ ), and then decreasing with depth to values lower than $0.5 \mathrm{~m} / \mathrm{s}$ at levels below $500 \mathrm{~m}$. As expected, the profile relative to the North Adriatic Sea reaches the absolute maximum $(3.8 \mathrm{~m} / \mathrm{s}$ at $20 \mathrm{~m})$, exhibiting values of up to $3 \mathrm{~m} / \mathrm{s}$ even at $160 \mathrm{~m}$. Referring to Fig. 7 and Sect. 3.1, we have highlighted in Table 2 those regions which present values of the standard deviation from the annual higher than $1.5 \mathrm{~m} / \mathrm{s}$ at four different depths: 50, 100, 200 and $400 \mathrm{~m}$. The North Atlantic box is the only area that keeps an intense signal down to $400 \mathrm{~m}$, while only the southeastern Mediterranean has a standard deviation higher than $1.5 \mathrm{~m} / \mathrm{s}$ at $200 \mathrm{~m}$, which is mainly due to the presence of the gyres. A consequence of the spatial average in this area is the cancellation of the strong signal relative to the Nile Delta, which is permanent up to a $400 \mathrm{~m}$ depth (see Fig. 7).

In Figs. 9 and 10, we show the annual mean SS profile for each area, and its computed temporal standard deviation $\sigma_{t}$ in the layer between 5 and $500 \mathrm{~m}$. A common aspect among all the SSPs is the strong seasonal variation in the near-surface layer. At $5 \mathrm{~m} \sigma_{t}$, relative to the Mediterranean areas, is between $7.8 \mathrm{~m} / \mathrm{s}$ (Aegean Sea) and $12.4 \mathrm{~m} / \mathrm{s}$ (North 


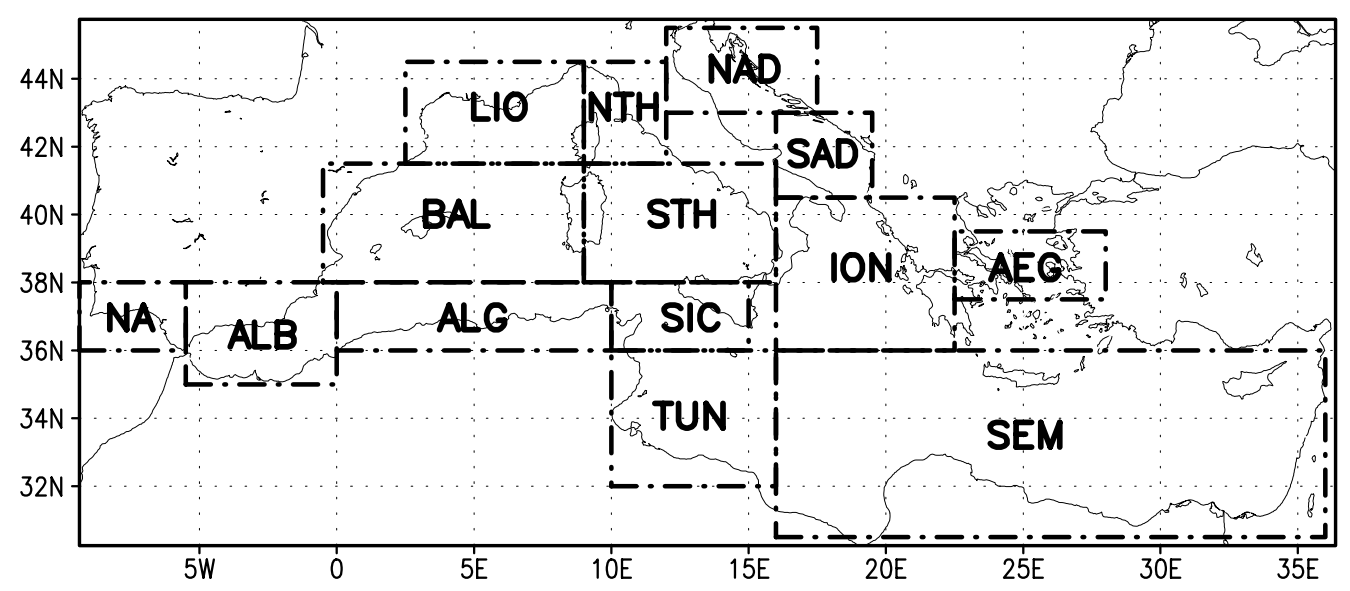

Fig. 8. Areas' subdivision: North Atlantic box (NA), Alboran Sea (ALB), Gulf of Lions (LIO), Balearic Basin (BAL), Algerian Sea (ALG), North Tyrrhenian Sea (NTH), South Tyrrhenian Sea (STH), Sicily Strait (SIC), Tunisian/Lybian Sea (TUN), North Adriatic Sea (NAD), South Adriatic Sea (SAD), Ionian Sea (ION), Aegean Sea (AEG), South-East Mediterranean Sea (SEM).

Adriatic); at $20 \mathrm{~m}$ it oscillates from $6 \mathrm{~m} / \mathrm{s}$ (Alboran Sea) to $10 \mathrm{~m} / \mathrm{s}$ (Tunisian/Lybian Sea). Sound speed decreases to $100 \mathrm{~m}$, where a more or less pronounced minimum is found. The strong variability in the upper layers is devoted mainly to the seasonal temperature variations, while the effects due to the presence of different water masses tend to disappear when averaging on wide areas (as in the case of the strong signal of the Nile Delta, now gone). In the North Atlantic area, upper layers' variability is lower than in the Mediterranean: $5.6 \mathrm{~m} / \mathrm{s}$ at $5 \mathrm{~m}$ and $4.6 \mathrm{~m} / \mathrm{s}$ at $20 \mathrm{~m}$. Below $100 \mathrm{~m}$, as temperature and salinity remain almost constant, the effect of pressure increases the sound speed, while $\sigma_{t}$ strongly drops: at $520 \mathrm{~m}$ standard deviations are lower than the SS computation error estimated in Eq. (9), in most of the areas, except for the Gulf of Lions, the South Adriatic Sea and the Aegean Sea, areas of dense water formation.

The North Adriatic Sea shows an anomalous SSP: the minimum below the thermocline is located around $50 \mathrm{~m}$, while at $100 \mathrm{~m}$ there is a relative maximum, then SS decreases. Surface SS variability is high: for the strong Bora wind and the shallow depth of this area, low temperatures are reached during winter (causing mean annual SS values at $5 \mathrm{~m}$ lower than $1508 \mathrm{~m} / \mathrm{s}$, with localised minima values lower than $1490 \mathrm{~m} / \mathrm{s}$ in February and March in the Gulf of Venice), nevertheless, warm waters are found in summer. The presence of river outflows, from the Po River in particular - a freshwater source that induces one of the strongest salinity anomalies in the Mediterranean - and the intense evaporation occurring during Bora events are responsible for the strong salinity variability observed in this region. Also, the South Adriatic Sea shows a noteworthy variability beyond a $100 \mathrm{~m}$ depth, with a $\sigma_{t}$ of around $1.2 \mathrm{~m} / \mathrm{s}$. It is a known fact that the strong water exchange in the Otranto Channel, influences mainly the SS variability of this area. The signature of LIW is well recognizable only in the Aegean Sea profile by a weak relative maximum around $450 \mathrm{~m}$.

\subsection{EOF results}

The Mediterranean basin was divided into 14 areas for which the EOF analysis was performed by using monthly mean profiles computed on each area. This synthetic description of the SS field on a regional basis provides the mean profiles and EOF coefficients to be used as reference for the area. In addition, since the data used are climatological, smoothed, and spatially averaged, the SS standard deviations describe the minimum variability we can expect in each area, and allow us to evaluate if the seasonal fluctuation is strong enough to be detected by tomographic applications. This means that the variability associated with the EOF deviation is always less than the variability associated with the real deviation, since the averaging processes can be seen as low-pass filters in frequency. In the histogram shown in Fig. 11, the relative importance of the first four eigenfunctions for each area are plotted. The $y$-axis is logarithmic, in order to also evidence the contribution of the high-order eigenfunctions. The first mode explains more than $90 \%$ of the variability, in particular, for 12 of the 14 areas the contribution relative to the first eigenfunction varies from $93 \%$ in the Aegean Sea to 97\% in the Alboran Sea. The two areas with lower weight are the North Atlantic (87.7\%) and the North Adriatic Sea (89.3\%), the contribution due to the second mode are $11.1 \%$ and $9.85 \%$, respectively. For the other areas the second mode accounts for from $2.69 \%$ (Alboran Sea) to $6.11 \%$ (Aegean Sea). The second mode is generally slightly higher in the Eastern Mediterranean than in the Western. The higher mode contributions are negligible, in general, at lower than $1 \%$. From these results, following Sect. 2.3, we have represented the 14 SSP deviations by a linear combination of only two dominant eigenfunctions, $F_{1}(z)$ and $F_{2}(z)$, and their associated time coefficients, $\alpha_{1}(t)$ and $\alpha_{2}(t)$, introducing a maximum error of the order of $1 \%$ :

$\Delta c(z)=\alpha_{1}(t) F_{1}(z)+\alpha_{2}(t) F_{2}(z)$. 

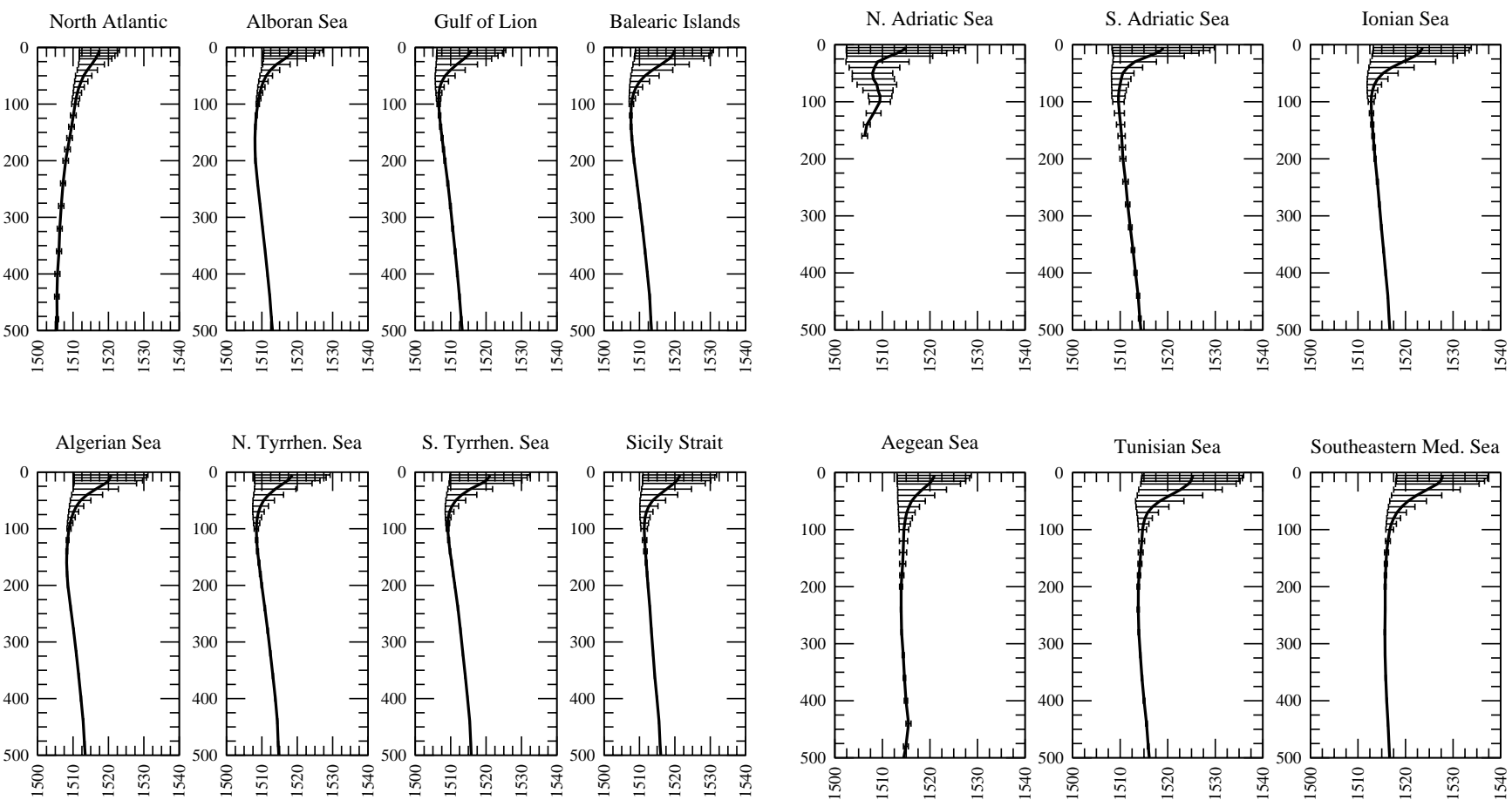

Fig. 9. West Mediterranean: annual mean sound speed profile $(\mathrm{m} / \mathrm{s})$ and relative computed temporal standard deviation $\sigma_{t}$ between a 5 and $500 \mathrm{~m}$ depth.

SSP deviations obtained by using only the first two EOFs differ from those of the original profiles between a minimum of $0.2 \%$ for the Alboran Sea and a maximum of $1.2 \%$ for North Atlantic box. In terms of sound speed, the difference between the original profile and that obtained by using only two modes, is about $0.86 \mathrm{~m} / \mathrm{s}$ for the worst case (North Atlantic in August at a $5 \mathrm{~m}$ depth), and only $0.12 \mathrm{~m} / \mathrm{s}$ for the better one (Alboran Sea, in August, at a $5 \mathrm{~m}$ depth). To validate the reliability of the method explained in Sect. 2.3 to our data, we have compared the values obtained by the EOF linear combination with four monthly SSP deviations at $50 \mathrm{~m}$ (Fig. 12). The areal mean, on which we have characterized the reliability of the EOF analysis, gives us a sufficient condition to provide the evidence of a strong signal, appropriate for tomographic applications. In this sense, for what concerns us, the EOF estimation is correct within the uncertainty associated with areal averaging, and corroborates our approach. In Fig. 13 and Fig. 14, the two first eigenfunctions between 5 and $500 \mathrm{~m}$ and the associated monthly coefficients are shown for each area, respectively, for the Western and Eastern Mediterranean Sea (as $\Delta c(z)$ is in $\mathrm{m} / \mathrm{s}$, and time coefficients have no unit measure, the eigenfunctions are measured in $\mathrm{m} / \mathrm{s}$ ). The signal in the first eigenfunction profile is concentrated in the upper layers, where the effects of seasonal variability are more intense, and is near zero below $100 \mathrm{~m}$, except for the profile relative to the North Atlantic box that has slightly negative values.

The trend of temporal coefficients associated with the first mode is common among all the areas, following the seasonal

Fig. 10. East Mediterranean: annual mean sound speed profile $(\mathrm{m} / \mathrm{s})$ and relative computed temporal standard deviation $\sigma_{t}$ between a 5 and $500 \mathrm{~m}$ depth.

cycle of sea surface temperature, with the minimum between February and March, and the maximum between August and September. A nonlinear best-fit using a sinusoidal function was applied to the time coefficient associated with the first mode, $\alpha_{1}(t)$, to evidence a possible phase shift in the annual cycle among the different areas:

$\alpha_{1}(t)=A_{0} \cos \left(\frac{2 \pi}{12}\left(t+A_{1}\right)\right)$.

Computing Eq. (15) among all the areas, the coefficient $A_{0}$ resulted as 16.0 for the North Atlantic box, around 22 for the Alboran Sea and the Aegean Sea, and between 27.1 and 33.7 for all the other areas. Concerning coefficient $A_{1}$, the sinusoidal fit has computed quite a uniform response, in correspondence to month 8.2-8.7 for all the regions, indicating that the maximum is normally performed in mid-August. Even though the winter minimum is around February in the northwestern Mediterranean regions and tends to be in March in the eastern ones, the estimated phase shifts in the different areas turn out to be below the sampling time (1 month). Similar results were obtained in the Eastern Mediterranean by Marullo et al. (1999) for the sea surface temperature seasonal variability measured with the advanced, very high resolution radiometer (AVHRR).

The second mode eigenfunction profiles are negative at the near surface and increase toward positive values, with a maximum located at $40-50 \mathrm{~m}$, in correspondence to the change in the second derivative of the first eigenfunction. As in the case of the first mode, the second one also decreases rapidly 


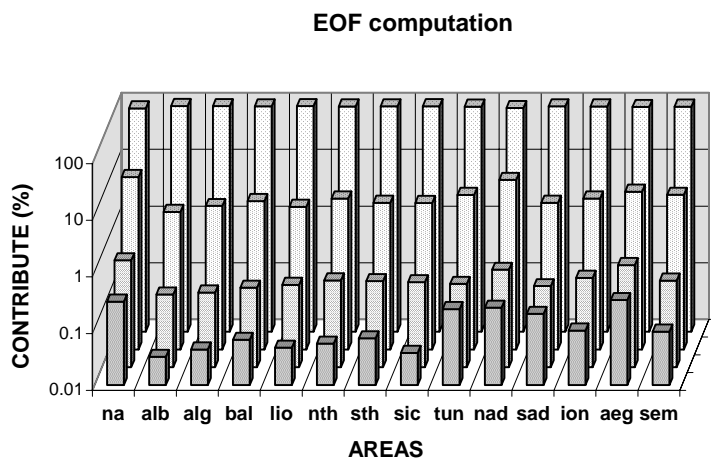

口MODE4 口MODE3 口MODE2 $\square$ MODE1

Fig. 11. Contributes of the first four eigenfunctions for each area (y-axis is logarithmic).

to zero, approaching levels below a $100 \mathrm{~m}$ depth, with the exception of the North Atlantic, which maintains at positive values, probably a signature of LIW, and the South Adriatic with positive values up to $500 \mathrm{~m}$. The amplitude of the time coefficient for the second mode is less than one-half that of the first, and the time cycle differs more between the two, as it also contains some variability associated with water mass distribution and dynamical characteristics of each area. Nevertheless, some common features can be associated with the evolution of the vertical structure. The November maximum occurs when the thermocline is eroded rapidly, thus changing from a summer situation to a winter one. During the winter months, in particular, in the northwestern regions, the coefficients are small or nearly zero: the profiles in this period are uniform with a small increase with depth - so they can be considered almost barotropic - and remain quite constant in time. The formation of the thermocline occurs slowly with respect to the rapidity of the erosion: it begins around April and reaches its maximum in late August.

\section{Discussion}

The results of this study are arranged as follows: sound speed characteristics and seasonal variability in the Mediterranean, EOF analysis, and the salinity impact on the tomographic inversion.

\subsection{Sound speed characteristics in the Mediterranean Sea}

Sound speed in the Mediterranean displays a wide range of variability, both seasonal and spatial. It is concentrated mainly in the upper $200 \mathrm{~m}$, where the effects of the atmospheric interaction are more intense; nevertheless, fronts and persistent gyres, as well as different water masses, also affect the sound speed at higher depths. Sound speed spatial distribution, in the upper thermocline region, reflects well that of the temperature, presenting a northwest-southeast gradient with a winter minimum sound speed of around $1490 \mathrm{~m} / \mathrm{s}$, located in the shallow northern areas of the Adriatic Sea and the Gulf of Lions and maxima $(1530 \mathrm{~m} / \mathrm{s})$ in front of the easternmost Mediterranean coasts. In spite of the smoothed cli-
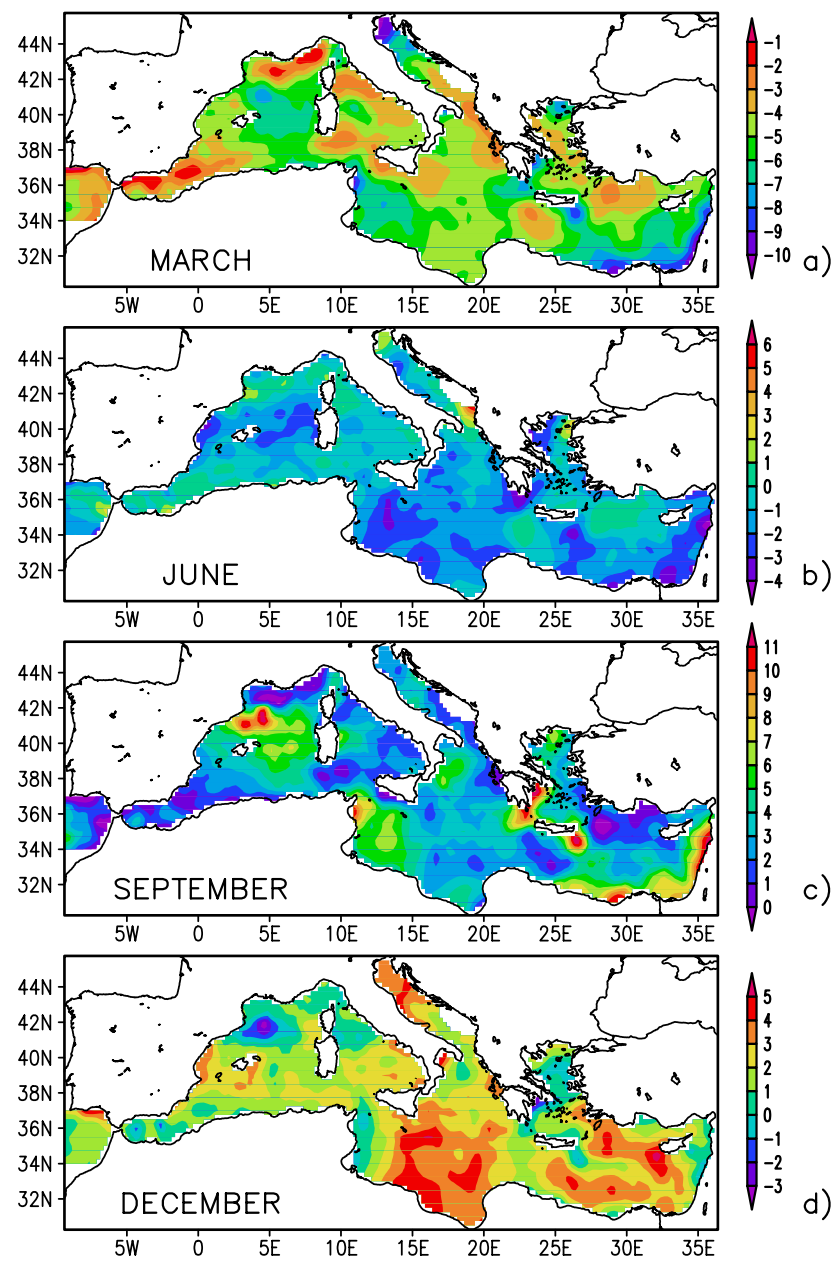

Fig. 12. Sound speed monthly deviation (m/s) at $50 \mathrm{~m}$ in March (a), June (b), September (c) and December (d).

matological field examined here, some structures revealed up to high depths - horizontal gradients and a standard deviation associated with seasonal variation strong enough to be successfully detected by acoustic tomography. The annual mean vertical sound speed profile for the Mediterranean is characterised by a strong decrease in the surface layer from about $1523 \mathrm{~m} / \mathrm{s}$ down to a depth of around $100 \mathrm{~m}$. Here the minimum $(1513 \mathrm{~m} / \mathrm{s})$ is found within a uniform layer of about $70 \mathrm{~m}$ in thickness, increasing constantly with depth $(1540 \mathrm{~m} / \mathrm{s}$ around $2000 \mathrm{~m})$ right down to the bottom. A signature of the LIW can be observed between a $450 \mathrm{~m}$ and $550 \mathrm{~m}$ depth, where the derivative of sound speed with depth decreases with respect to that of the surrounding layers but it is unlikely that this could be easily resolved by means of acoustic tomography, unless they occur during some specific events (Send et al., 1995). Some differences can be observed between the eastern and the western basins and among different regions. In the eastern basin, sound speed is higher than in the western part, with the minimum located a few tens of meters deeper and the layer with almost constant or weakly increasing sound speed is thicker, more than $150 \mathrm{~m}$. 

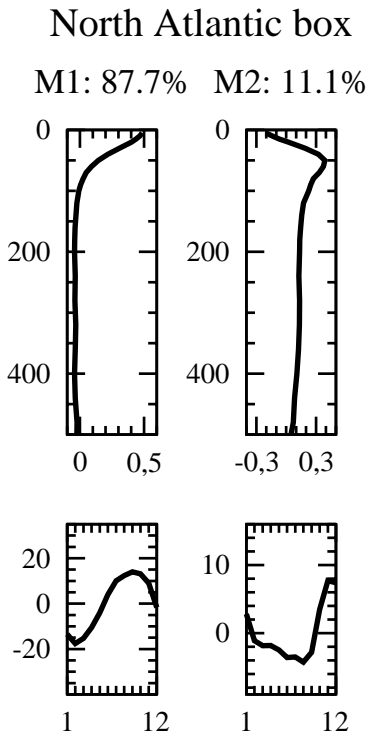

North Tyrrhen. Sea
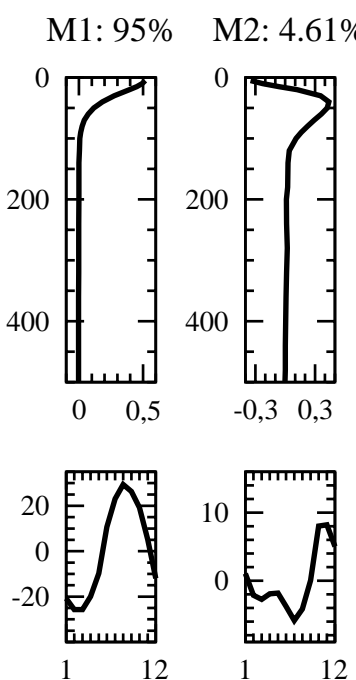

Alboran Sea
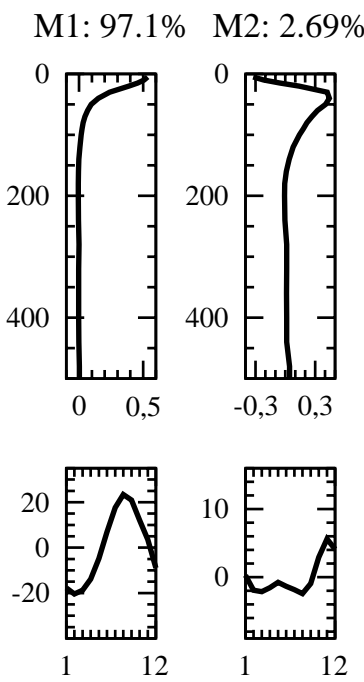

South Tyrrhen. Sea
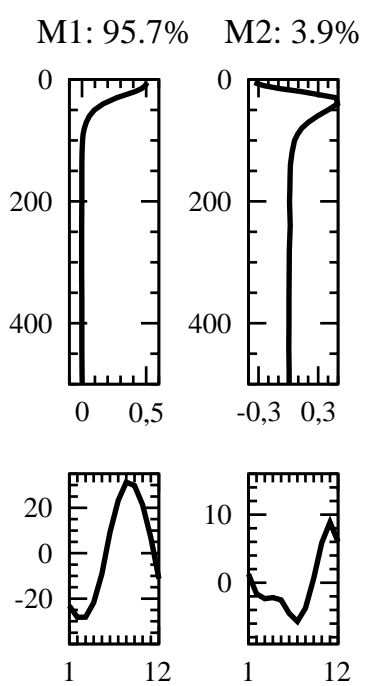

Balearic Islands
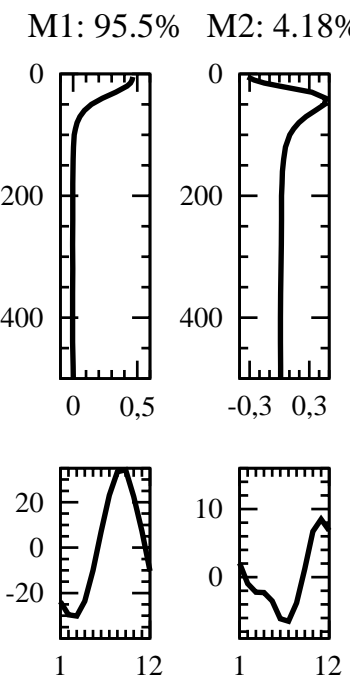

Sicily Strait

$$
\text { M1: } 95.8 \% \text { M2: } 3.87 \%
$$
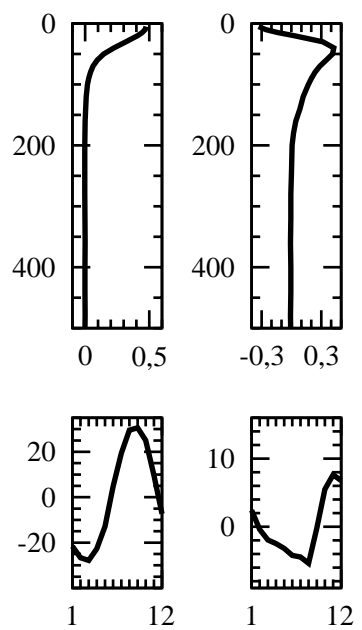

Gulf of Lion
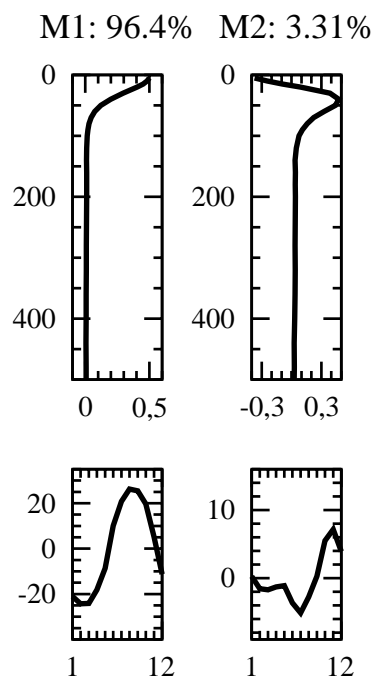

Algerian Sea

$$
\text { M1: } 96.3 \% \text { M2: } 3.42 \%
$$
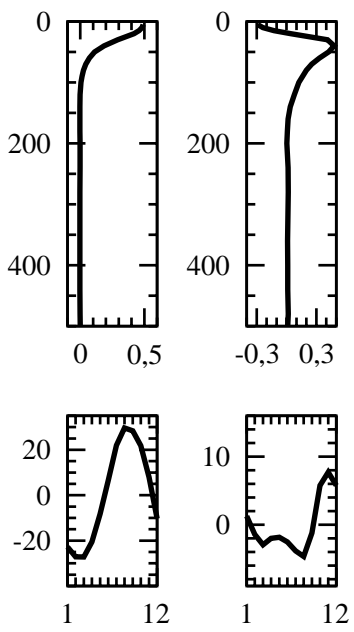

Fig. 13. West Mediterranean: eigenfunctions $F_{1}(z)$ and $F_{2}(z)(\mathrm{m} / \mathrm{s})$ between 5 and $500 \mathrm{~m}$, and the associated coefficients $\alpha_{1}(t)$ and $\alpha_{2}(t)$.

In the northern regions, during winter, the mixed layer can reach high depths, thus leading to an almost vertically homogeneous profile with a smooth increase due to increasing depth. Mediterranean SSPs differ from those in temperate zones of the open oceans (Munk et al., 1995), mainly for a well-pronounced minimum below the seasonal thermocline and for the absence of the deep SOFAR channel - generally located between 800 and $1200 \mathrm{~m}$, with values at the axis minimum at mid-latitudes up to $1480 \mathrm{~m} / \mathrm{s}$ (see Flatté et al., 1979, for the Pacific Ocean; Northup and Colborn, 1974, for the Atlantic Ocean) - which characterises sound speed propagation in the oceans. This is due to the thermal vertical structure of the Mediterranean Sea, characterised by a reduced or absent permanent thermocline and by warmer deep waters. The characteristics of sound speed propagation can change, according to the season and the geographic region, from a channelled propagation during summer to surface reflected during strong winter cooling periods in the northern regions.

\subsection{EOF analysis}

The EOF analysis, on averaged regional monthly mean profiles, has shown that two modes are able to explain more than $98 \%$ of variability, about $95 \%$ of which is accounted for by the first one. Even though the time and spatial averaged profiles analysed here cannot completely resolve the small-scale vertical structure, the use of a two-dimensional parameter space for the inversion analysis is widely accepted (Shang and Wang, 1994). The base for EOF decomposition for different regions and the relative monthly mean coefficients provided here can thus be considered as an important tool when approaching inverse problems, mitigating the need 

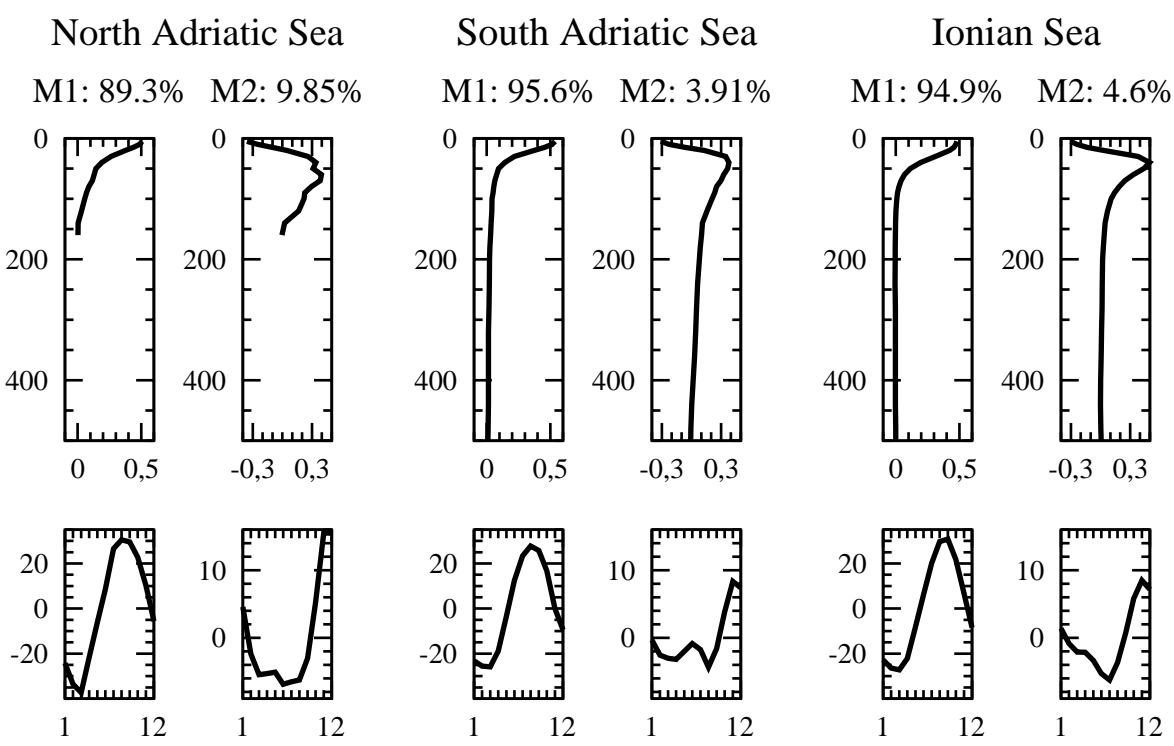

Tunisian Sea

M1: $94.1 \%$ M2: $5.34 \%$

Aegean Sea
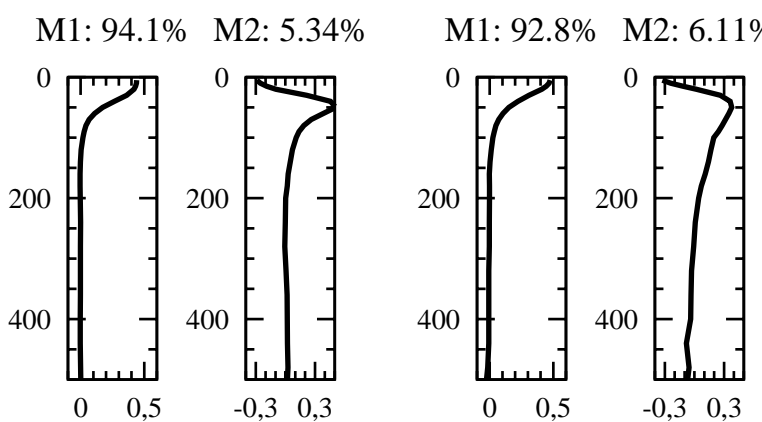

\section{South-East Med. Sea}

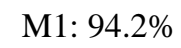

M2: $5.37 \%$
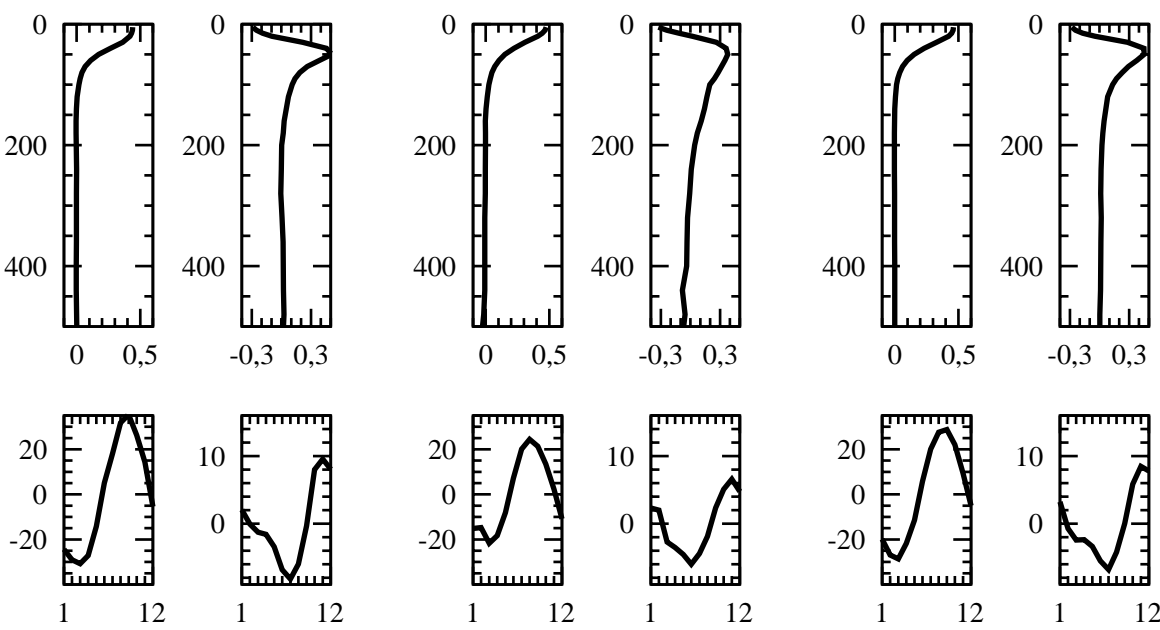

Fig. 14. East Mediterranean: eigenfunctions $F_{1}(z)$ and $F_{2}(z)(\mathrm{m} / \mathrm{s})$ between 5 and $500 \mathrm{~m}$, and the associated coefficients $\alpha_{1}(t)$ and $\alpha_{2}(t)$.

of exhaustive monitoring of physical parameters during tomographic experiments. The EOF analysis based on SSPs obtained by data interpolated on a regular grid does not generate additional error, on average, as demonstrated in Appendix A.

\subsection{Salinity profiles and the tomographic inversion}

In the inversion, the climatological salinity profile can help if explicitly introduced in the backward calculation of temperature from the SS field. This gives an average improvement of $0.21 \mathrm{~m} / \mathrm{s}$, compared with the typical variability of SS in the upper $700 \mathrm{~m}$, which accounts for $2.12 \mathrm{~m} / \mathrm{s}$ (and $1.78 \mathrm{~m} / \mathrm{s}$ between 50 and $700 \mathrm{~m}$, a suitable layer for tomographic applications - as in Sect. 2.2., this averaged SS mean has been estimated from the MED6 data set). The higher relative importance of the salinity contribution can be foreseen if pre- cise estimates are expected for the layer below the seasonal thermocline, where the seasonal signal of the temperature is much weaker.

\section{Conclusions}

To summarize, the analysis of the sound speed field in the Mediterranean, based on a climatological data set, allows us to highlight three points:

1. The definition of regions where the variability is sufficient to successfully apply acoustic tomography;

2. The computation of a reduced EOF set and its time evolution is able to reproduce correctly SS profiles within each zone, thus providing an operational base for Matched Field Tomography; 
3. The importance of the integration of climatological salinity profiles in the inversion process cannot be disregarded in the Mediterranean Sea. As a consequence, we demonstrated how a climatological data set can help to identify regions and exploit existing knowledge for successful tomographic experiments.

\section{Appendix A}

We want to demonstrate that the estimation error of the mean value of a random variable calculated starting from experimental data can be higher than that one obtained from an interpolated set of the same data. Let $G$ be a random variable, supposed ergodic, defined with a normal distribution $\left(\mu, \sigma_{r}\right)$ on an area $\mathrm{A}$, and let $\left\{G_{k}^{r}, k=1, N\right\}$ be $N$ realizations of $G$ associated with a statistical variable $\varepsilon$, defined with a normal distribution $\left(0, \sigma_{\varepsilon}\right)$, which represents the experimental uncertainty. Let us define an arithmetic mean estimator $\boldsymbol{A}^{T}=(1 / N \ldots 1 / N)$, in a vector form, such that the mean can be written as $\mu=\boldsymbol{A}^{T}\left(\boldsymbol{G}^{r}+\boldsymbol{\varepsilon}\right)$. The estimation error associated to the mean is, therefore,

$$
\frac{\sigma_{A}}{\sqrt{N}}=\frac{\sqrt{\sigma_{r}^{2}+\sigma_{\varepsilon}^{2}}}{\sqrt{N}}
$$

that is the squared sum of the variance estimate relative to the random variable and that relative to the experimental uncertainty. The interpolated gridded data set $\boldsymbol{G}^{i}$ is defined in terms of a interpolation matrix $\mathbf{W}: \boldsymbol{G}^{i}=\mathbf{W} \boldsymbol{G}^{r}$. The interpolation matrix represents the minimum variance linear unbiased estimator obtained from the Gauss-Markov theorem, which provides the theoretical background to a large class of objective analysis methods used in meteorology and oceanography - see, for example, the seminal papers of Gandin (1965) and Bretherton (1976). Recalling the results obtained in these works and referring to the paper by Crise and Manca (1992), $\mathbf{W}$ is derived by the composition of the two matrices: $\mathbf{R}_{\mathbf{0}}$, that represents the covariance between a point of the gridded data set and a measured point, and the inverse of $\mathbf{R}_{\mathbf{i j}}$, which is proportional to the matrix of the covariance between all pairs of observations with a contribution due to the experimental error variance. Under the above hypotheses the estimation error for each element $G_{0}^{i}$ of the gridded data set is:

$$
\begin{aligned}
\sigma_{W}^{2} & \equiv\left\langle\left(G_{0}-\hat{G}_{0}\right)^{2}\right\rangle \\
& =\sigma_{A}^{2}\left\{1-\sum_{i j} \rho_{0 i} \rho_{0 j} \mathbf{R}_{i j}^{-1}+\frac{\left(1-\sum_{i j} \rho_{0 i} \mathbf{R}_{i j}^{-1}\right)^{2}}{\sum_{i j} \mathbf{R}_{i j}^{-1}}\right\},
\end{aligned}
$$

where $\rho_{0 i}$ is the autocorrelation function, and the variance is obtained as the sum of three contributions: the first acts as if the process was uncorrelated, the second depends on the covariance function and the third is related to the estimation error of the mean $\mu$, supposed unknown. Generally, for efficiency and numerical stability reasons, a range influence is established, in order to take into account only a limited number of realizations close to the estimation point. In this sense, the mean can be estimated with a local average which mitigates the effect of the background deterministic signal. If:

$$
\frac{\left(1-\sum_{i j} \rho_{0 i} \mathbf{R}_{i j}^{-1}\right)^{2}}{\sum_{i j} \mathbf{R}_{i j}^{-1}}>\sum_{i j} \rho_{0 i} \rho_{0 j} \mathbf{R}_{i j}^{-1},
$$

then the squared estimation error of each interpolated value is lower than its estimated squared variance $\sigma_{A}^{2}$. The error associated with the mean of $G^{i}$, defined as $\hat{\mu}=\boldsymbol{A}^{T} \boldsymbol{G}$, is:

$\hat{\sigma} \equiv \frac{\sigma_{A}}{\sqrt{N}} \sqrt{1-\sum_{i j} \rho_{0 i} \rho_{0 j} \mathbf{R}_{i j}^{-1}+\frac{\left(1-\sum_{i j} \rho_{0 i} \mathbf{R}_{i j}^{-1}\right)^{2}}{\sum_{i j} \mathbf{R}_{i j}^{-1}}}$.

In the case of the algebric sum of the correlation function, the number of experimental points and their spatial distribution yields

$\left\{1-\sum_{i j} \rho_{0 i} \rho_{0 j} \mathbf{R}_{i j}^{-1}+\frac{\left(1-\sum_{i j} \rho_{0 i} \mathbf{R}_{i j}^{-1}\right)^{2}}{\sum_{i j} \mathbf{R}_{i j}^{-1}}\right\}<1$

then $\hat{\sigma}<\frac{\sigma_{A}}{\sqrt{N}}$.

The above demonstration proves that the estimation of the mean starting from the interpolated data can be even better than that obtained by a direct averaging procedure on the measures.

Acknowledgements. This work was carried out in the frame of the TOMPACO project, included in the Italian program "Mediterranean Environment: analysis and assessment of observation methodologies" partially supported by MIUR. The MED6 temperature and salinity data set in its original form was kindly made available by N. Pinardi. The OGS authors wish to thank V. Mosetti for her support in the computations. The authors wish also to thank the useful comments made by the referees.

Topical Editor N. Pinardi thanks R. Onken and another referee for their help in evaluating this paper.

\section{References}

ATOC Consortium (Baggeroer, A. B., Birdsall, T.G., Clark, C. Colosi, J. A., Cornuelle, B. D., Costa, D., Dushaw, B. D., Dzieciuch, M., Forbes, A. M. G., Hill, C., Howe, B. M., Marshall, J., Menemenlis, D., Mercer, J. A., Metzger, K., Munk, W., Spindel, R. C., Stammer, D., Worcester, P.F., and Wunsch, C.): Ocean climate change: comparison of acoustic tomography, satellite altimetry, and modelling, Science, 281, 1327-1332, 1998.

Brankart, J.M. and Pinardi, N.: Abrupt cooling of the Mediterranean Levantine Intermediate Water at the beginning of the 1980s: observational evidence and model simulation, J. Phys. Oceanogr., 31, 2307-2320, 2001.

Brasseur, P., Beckers, J. M., Brankart, J. M., and Schoenauen, R.: Seasonal temperature and salinity fields in the Mediterranean Sea: Climatological analyses of an historical data set, Deep-Sea Res., 43, 159-192, 1996. 
Bretherton, F.P., Davis, R.E., and Fandry, C. B.: A technique for objective analysis and design of oceanographic experiments applied to MODE-73, Deep-Sea Res., 23, 559-582, 1976.

Chen, C. T. and Millero, F. J.: The Sound Speed in Seawater, J. Acoust. Soc. Am., 62, 1129-1135, 1977.

Clay, C.S. and Medwin, H.: Acustical Oceanography, WileyInterscience, New York, 1977.

Crise, A. and Manca, B.: Digital thematic maps from CTD measurements. A case study in the Adriatic Sea, Boll. Geof. Teor. Appl., 10, 15-40, 1992.

Davis, R.E.: Predictability of sea surface temperature and sea level pressure anomalies over the North Pacific Ocean, J. Phys. Oceanogr., 6, 249-266, 1976.

Del Grosso, V. A.: New equations for the speed of sound in natural waters (with comparison to other equations), J. Acoust. Soc. Am., 56, 1084-1091, 1974.

Demoulin, X., Stephan, Y., Jesus, S., Coelho, E., and Porter, M. B.: INTIMATE96: a shallow water tomography experiment devoted to the study of internal tides, Proc. of SWAC'97, Beijing, 1997.

Dushaw, B. D., Worcester, P. F., Cornuelle, B. D., and Howe, B. M.: On equations for the speed of sound in sea water, J. Acoust. Soc. Am., 93, 255-275, 1993.

Flatté S. M., Dashen, R., Munk, W., Watson, K., and Zachariasen, F.: Sound Transmission Through a Fluctuating Ocean, Cambridge University Press, 1979.

Gandin, L.S.: Objective analysis of meteorological fields, No. 1373, Israel Program for Scientific Translation, Jerusalem, 1965.

Giorgetti, A.: Climatological analysis of the Adriatic Sea thermohaline characteristics, Boll. Geof. Teor. Appl., 40, 53-73, 1999.

Jensen, F. B., Kuperman, W. A., Porter, M. B., and Schmidt, H.: Computational Ocean Acoustics, AIP Series in Modern Acoustics and Signal Processing, 1994.

Le Vourch, J., Millot, C., Castagne, N., Le Borgne, P., and Olry, J.P.: Atlas des fronts thermiques en mer Méditerranée d'aprés l'imagerie satellitaire, Musée Océanographique Monaco, 1992.

MacKenzie, K. V.: Nine-term equation for sound speed in the oceans, J. Acoust. Soc. Am., 70, 807-812, 1981.
Marullo S., Santoleri, R., Malanotte-Rizzoli, P., and Bergamasco, A.: The sea surface temperature field in the Eastern Mediterranean from advanced very high resolution radiometer (AVHRR) data, Part I: Seasonal variability, J. Mar. System, 20, 63-81, 1999.

MEDATLAS Group: Specifications for Mediterranean Data Banking and regional quality controls, SISMER Rep. IS/94-014, 1994 (revised version 1995).

MODB: http://modb.oce.ulg.ac.be/

Morawitz, W. M. L., Sutton, P. J., Worcester, P. F., Cornuelle, B. D., Lynch, J. F., and Pawlowicz, R.: Three-dimensional observations of a deep convective chimney in the Greenland Sea during winter 1988/1989, J. Phys. Oceanogr., 26, 2316-2343, 1996.

Munk W., Worcester, P., and Wunsch, C.: Ocean Acoustic Tomography, Cambridge University Press, 1995.

Munk, W.: Acoustic thermometry of ocean climate, J. Acoust. Soc. Am., 100, 2580, 1996.

Northrup, J. and Colborn, J. G.: Sofar channel axial sound speed and depth in the Atlantic Ocean, J. Geophys. Res., 79, 56335641, 1974.

Pawlowicz, R., Lynch, J.F., Owens, W. B., Worcester, P.F., Morawitz, W. M. L., and Sutton, P. J.: Thermal evolution of the Greenland Sea Gyre in 1988-1989, J. Geophys. Res., 100, 4727 4750, 1995.

Send, U., Schott, F., Gaillard, F., and Desaubies, Y.: Oberservation of a deep convection regime with acoustic tomography, J. Geophys. Res., 100, 6927-6941, 1995.

Send, U., Krahmann, G., Mauuary, D., Desaubies, Y., Gaillard, F., Terre, T., Papadakis, J., Taroudakis, M., Skarsoulis, E., and Millot, C.: Acoustic observations of heat content across the Mediterranean Sea, Nature, 385, 615-617, 1997.

Shang, E. C. and Wang, Y. Y.: Tomographic inversion of the El Niño profile by using a matched-mode processing (MMP) method, IEEE J. Ocean. Engin., 19, 208-213, 1994.

Weare, B.C., Navato, A.R., and Newell, R.E.: Empirical orthogonal analysis of Pacific Sea surface temperatures, J. Phys. Oceanogr., 6, 671-678, 1976. 